\title{
Determination of the Optimum Berth Number of the Izmir Seaport by Deterministic and Probabilistic Methods Based on Artificial Neural Networks
}

\author{
Ümit Gokkus and Mehmet Sinan Yildirim* \\ ${ }^{1}$ Manisa Celal Bayar University, Manisa, Turkey \\ mehmetsinan.yildirim@cbu.edu.tr*
}

\begin{abstract}
Seaports are among the vital requirements of a country's trade. The service capacity of a seaport is important to maintain seaport operations. Determining the number of the berthing places is a major decision for planning a seaport by considering the future port capacity. Queuing theory is used to determine the optimum berth number in a seaport. In this study, optimum number of berths of Izmir seaport in Turkey was determined by implementing the queuing theory. Likewise, the ship traffic was predicted using two forecasting models: Linear Regression Analysis and Artificial Neural Networks. Model results were candidates of input variables for the queueing model for estimating the feasible berth numbers between 2015 and 2023. For 2015, feasible number of berthing places was found as 14 and for 2023 it was found as 16 by the queuing theory.
\end{abstract}

Keywords: Berth Capacity, Optimization, Seaport Planning, Port Feasibility, Queuing Theory

\section{Introduction}

Berths are among the important facilities of a seaport providing a suitable service place for ships to handle goods. In the designing stage, the number of berths is an important factor influencing the total investment cost of a seaport. Berth configuration is determined with considering the size, tonnage and draft of the arriving ships. Determining the optimum number of berths in a seaport is the principle decision must be taken before the overall design procedure. The ideal number of berths, expected to serve the handling operations for the arriving ships without any delays, strongly linked with the service capacity of a seaport and the ship traffic. In case of insufficient number of berths, there will be a queue of ships so additional penalty fees subjected to be paid to ship owners. Also, the waiting ships in the queue may check the nearby idle seaports yielding a loss of income. In contrary, idle berths indicating a lower operation efficiency, are not desirable in a seaport. In this study, the optimum berth number for the Izmir seaport in Turkey was determined for upcoming years by implementing both deterministic and probabilistic berth capacity analysis based on the queuing theory. Both Linear Regression (LR) and Artificial Neural Network (ANN) models were considered in this study to predict the future port traffic by implementing the best performing model.

\section{Literature Review}

Designing an optimum seaport is a challenging problem for many planners and decision makers. As a preliminary stage, determining the optimum number of berths is the first step in the seaport planning. There were many studies determining the optimum number of berths at a seaport such as [1-3]. Nicolau [4] implemented the queuing theory to determine the optimum number of berths. Morse [5] indicated several expressions 
allowing determination of the optimum berth occupancy. In his study, optimum berth configuration was obtained with a minimum cost criteria. Fratar et al., [6] studied the maximum berth occupancy for a seaport and indicated that, the ship arrival traffic and ship service time could be represented with the Poisson's and the exponential distributions. In literature, there exist several studies considering the port of Izmir. Eren and Gokkus [7] predicted the storage area requirements by performing the traffic projection of Izmir port. Budak [8] implemented both queuing theory model and port capacity analysis in optimizing the storage area.

\section{Methodology}

In a seaport, determination of the optimum number of berths is a major optimization problem. Usually, the objective of a planner is to find the most economical berth configuration considering the economic aspects. Queuing theory, integrated with a cost optimization including service and waiting costs of the ships can be used for determining the optimum number of berths. The results of the model integrated with a cost optimization consist of service and waiting costs of the ships. The model considers the fact of if arriving rate of the ships to the seaport is smaller than the ship service rate (number of handled ships per a time interval) then unemployed berths will be emerged yielding idle berths and lower service efficiency of the seaport. In contrast, if the arriving rate of the ships is greater than the service rate, these ships will be taken to the queue. In the queue theory, arriving rate of the ships can be taken as deterministic or probabilistic. For the latter case, the probability distribution of the arriving ships can be characterized by the Poisson's distribution as Equation1.

$$
\mathrm{P}_{\mathrm{n}}=\frac{\lambda^{n} e^{-\lambda}}{\mathrm{n} !}
$$

Where, $P_{n}$ is the probability of " $n$ " ships arriving in a seaport in specific time, " $\lambda$ " is the average number of arrivals and " $\mathrm{e}$ " is the Euler's number (2.718). The summation of the probabilities indicating " $n$ " ships arriving in a specific period is equal to 1 . For a seaport, average number of arriving ships in a time period " $\lambda$ " can be determined by Equation 2.

$$
\bar{n}=\frac{T_{s}}{T}=\frac{\sum_{n=0}^{n} n f_{n}}{T}
$$

Where $f_{n}$ is the frequency indicating the number of days in which "n" number of ships arriving for a period of time " $T$ ". " $T_{s}$ " is the total time determined from the daily arrival records. The service time at a berth is the time spent for loading and unloading of the cargo for a single ship for a berth. This can be taken as constant or considered as variable. For the variable case, service time probability must be determined. A proper probability distribution can be fitted as a basic exponential curve. In this study, Erlang's K $(K=1)$ curve was used as shown in Equation3.

$$
S(>t b)=e^{-K b t b} \sum_{i=0}^{K-1}\left(K_{b} t_{b}\right)^{i} \frac{1}{i !}
$$

Where $\mathrm{K}=(1 \ldots \mathrm{N})$ is the Erlang number, $t_{b}$ is the berth occupancy time and " $\mathrm{b}$ " is the average service rate. The most proper distribution for ship arrivals and berth service time determined by the Chi-Square Goodness of Fit Test [9].

\subsection{Cost Analysis}

The method based on the determination of the unit cost of idle berths $\left(\mathrm{c}_{\mathrm{b}}\right)$ and idle ships $\left(c_{s}\right)$ for a seaport found with the following equations. For " $M$ " berths available in the 
seaport, the total cost of idle ships when $n-m>1$ and the cost of idle berths for the case of $m-n \geq 1$ can be found by Equation 4 .

$$
C_{M}^{T}=c_{s} \sum_{n=\mathrm{M}+1}^{n}(n-M) F_{n}+c_{b} \sum_{n=0}^{M-1}(M-n) F_{n} \quad\left\{C_{M-1}^{T}<C_{M}^{T}<C_{M+1}^{T}\right\}
$$

Where $F_{n}$ is the expcted frequency of arriving "n" ships, $C_{M}^{T}$ if the total cost, $C_{s}$ is the cost of waiting ships and $C_{b}$ is the cost of idle berths. The optimum berth number can be found by comparing the arrays of total costs generated for different berth numbers. The optimum cost refers to the best configuration of the berths in manner of its number represented by "M".

\subsection{Deterministic Method}

Nicolau [4] proposed a tabular method for determining the optimum number of berthing places in a seaport by implementing a tabular decision system considering occupied or idle berths. In this study, this methodology was used as the deterministic way. The operational parameters of the seaport which are queuing ratio and berth utilization ratio can be implemented for this deterministic procedure to evaluate the optimum berth number. The procedure can be implemented in a tabular format for " $\mathrm{M}$ " available berths. An example can be seen in Table 1 for each row, the probabilities of ship arrivals " $n$ " to a seaport are considered with their corresponding arrival rates.

Table 1. Tabular Procedure for Determining the Optimum Number of Berths in a Seaport

\begin{tabular}{|c|c|c|c|c|c|c|c|}
\hline \multirow[b]{2}{*}{$\begin{array}{rr}\begin{array}{l}\text { \# } \\
\text { ships }\end{array} & \text { of } \\
\text { port } & \end{array}$} & \multicolumn{3}{|c|}{$\begin{array}{l}\text { No of days or hours during } \\
\text { period T }\end{array}$} & \multicolumn{2}{|c|}{ M berths available } & \multicolumn{2}{|c|}{$\mathrm{M}+1$ berths available } \\
\hline & $F_{(n)}{ }^{\mathrm{T} P_{(n)}}=$ & $\mathrm{M}>\mathrm{n}$ & $\mathrm{n}>\mathrm{M}$ & $\begin{array}{l}\text { Cost of idle } \\
\text { Berths }\end{array}$ & $\begin{array}{c}\text { Cost of } \\
\text { Waiting Ships }\end{array}$ & $\begin{array}{l}\text { Vacant } \\
\text { Berths }\end{array}$ & Ships Waiting \\
\hline 0 & $F_{(0)}$ & $M F_{(0)}$ & - & $M c_{b} F_{(0)}$ & - & $(M+1) c_{b} F_{(0)}$ & - \\
\hline 1 & $F_{(1)}$ & $(M-1) F_{(1)}$ & - & $(M-1) c_{b} F_{(1)}$ & - & $(M) c_{b} F_{(1)}$ & - \\
\hline M-1 & $F_{(M-1)}$ & $F_{(M-1)}$ & - & $c_{b} F_{(M-1)}$ & - & $2 c_{b} F_{(M-1)}$ & - \\
\hline M & $F_{(M)}$ & None & None & None & None & $c_{b} F_{(M)}$ & \\
\hline $\mathrm{M}+1$ & $F_{(M+1)}$ & - & $F_{(M+1)}$ & - & $c_{S} F_{(M+1)}$ & None & None \\
\hline- & - & - & - & - & - & & $c_{S} F_{(M+2)}$ \\
\hline $\mathrm{n}$ & $F_{(n)}$ & - & $(n-M) F_{(n)}$ & - & $(n-M) c_{S} F_{(n)}$ & & $(n-M+1) c_{S} F_{(n)}$ \\
\hline
\end{tabular}

\subsection{Probabilistic Method}

In this study, the queuing theory was implemented as the probabilistic method. The aim of queuing theory is to get the principal performance measures of the system which are the probabilistic properties of the random variables such as number of the customers in the system, number of the waiting customers, utilization of the server, response and waiting time of a customer and idle-busy time of the server. In a seaport operation, when a ship arrives to the port, it is taken to an idle berth for good handling. Otherwise, it will be taken to the queue until the handling operations for the previous ships are finished. In this manner, queuing theory can be implemented after the system reaches the steady state for determining the optimum number of berths or servers in a seaport. As mentioned 
before, the arrivals of the ships to the seaport can be considered as deterministic or stochastic. As " $\lambda$ " is the average number of arrivals, " $1 / \lambda$ " is the average time elapsed between each successive arrivals. These successive arrival times can be considered with the exponential distribution. For implementing the queuing theory, the characteristics of the handling service for the ships must be well known. The service theory of the queuing system can be described as single or multi servers. The service rate " $\mu$ " is the service rate per a single time interval increment. Among the probability distributions describing the service time such as the Poisson and the Erlang distribution. The queue can be considered as infinitely long or a specific queue size. Ships in the queue can be selected by randomly, first come-first served or last come-first served methods. The following parameters summarize the characteristics of the queuing system with their corresponding indices.

(L): Average number of ships in the system. The total number of ships in the system which are either taking service or waiting.

(W): The average time spent per ship. The total time of a ship spent either in queue or system.

$\left(L_{q}\right)$ : Average queue length: The number of ships waiting for getting service.

$\left(W_{q}\right)$ : The average waiting time of ships in the queue $\left(\mathrm{W}_{\mathrm{q}}\right)$

$\left(W_{s}\right)$ : The average waiting time of ships in the system $\left(\mathrm{W}_{\mathrm{s}}\right)$

$(\rho)$ : Utilization ratio : The probability of the system if it is busy or not.

Queuing systems can be described with the Kendall notation for describing its characteristics with the following notation (See Equation5)

$$
(\mathrm{a} / \mathrm{b} / \mathrm{c}):(\mathrm{d} / \mathrm{e} / \mathrm{f})
$$

Where "a" is the distribution function of the inter-arrival times, " $b$ " is distribution function of the service times, "c" is number of servers, "e" is the total number of units is service and queue and " $\mathrm{f}$ " is the size of the arrival source. The following parameters are used in the Kendall notation for describing "a" and " $b$ " indices. Exponentially distributed random variables are notated by $\mathrm{M}$, meaning Markovian or "memoryless". As an example M/M/1 represents a system with Poisson arrivals and exponentially distributed service time and single server. $\mathrm{M} / \mathrm{G} / \mathrm{m}$ indicates with Poisson arrivals, generally distributed service time and $\mathrm{m}$-server system

The operation of berth at a seaport can be described with the queuing theory with multiple servers so "c" is described as the number of berths (See Equation9). If the number of arriving ships is smaller than the total number of servers $(n \leq c)$, there will be no queue as the service capacity is far enough for the incoming ships. On the contrary, for the case of $(n>c)$, " $n-c$ " number of ships will wait in the queue. This probability is described with Equation6 and Equation7. The probability of no ships are in the system is described with Equation8.

$P_{n}=(\lambda / \mu)^{n} \frac{P_{0}}{n !}=\rho^{n} \frac{P_{0}}{n !}$

$0 \leq n<c$ 


$$
\begin{array}{cc}
P_{n}=(\lambda / \mu)^{n} \frac{P_{0}}{c ! c^{n-1}} & n \geq c \\
=\rho^{n} \frac{P_{0}}{c ! c^{n-1}} & \\
P_{0}=\frac{1}{\sum_{n=0}^{c-1}(\lambda / \mu)^{n}+\left[\frac{1}{c !}(\lambda / \mu)^{c} \frac{c \mu}{c \mu-\lambda}\right]} & n \geq c
\end{array}
$$

Expected number of ships in the queue and in the system can be determined with Equation9. and Equation10.

$$
\begin{gathered}
L_{q}=\frac{\lambda \mu(\lambda / \mu)^{c}}{(c-1) !(c \mu-\lambda)^{2}} P_{0} \text { (9) } \\
L=\frac{\lambda \mu(\lambda / \mu)^{c}}{(c-1) !(c \mu-\lambda)^{2}} P_{0}+\lambda / \mu=L_{q}+\rho
\end{gathered}
$$

Expected waiting time in queue and system can be determined with Equation11 and Equation12.

$$
\begin{gathered}
W_{q}=\frac{\mu(\lambda / \mu)^{c}}{(c-1) !(c \mu-\lambda)^{2}} P_{0}=L_{q} / \lambda \\
W=\frac{\mu(\lambda / \mu)^{c}}{(c-1) !(c \mu-\lambda)^{2}} P_{0}+1 / \mu=W_{q}+1 / \mu
\end{gathered}
$$

The queuing parameters of the above equations yields the characteristics of the system for the steady condition. By considering period of the study, $T$, " $C S$ " be determined by Equation 13 where $L_{w}$ is determined from the queuing theory. $C_{s}$ is the unit price.

$$
C S=\left(C_{s}\right)(T)\left(L_{w}\right)
$$

\subsection{Ship Traffic Projection}

In order to forecast the container, cargo and passenger traffics in transportation systems, regression techniques can be employed. Beside the regression methods for the case of nonlinearity, a more flexible, approach is required for representing various types of nonlinear behaviors such as implementing ANN and Genetic Algorithm. In this study, a feed-forward ANN educated with back-propagation algorithm was used with the regression model.

3.4.1. Linear Regression Model: The generic regression problem $Y=f(X)$ is essentially a mapping from $\mathrm{X}$ to $\mathrm{Y}$. This empirical mapping can be performed using linear regression analysis. Linear regression is an appropriate tool for developing many empirical algorithms which is easy to apply In the case of linear regression, a linear model 
is constructed for transfer function. Multiple regression is a flexible modeling technique for examining the relationship of various independent variables to a single dependent variable [10]. The model can be described as Equation (14).

$$
Y=b_{0}+a_{1} X_{1}
$$

Where $b_{0}$ is the intercept and $a_{n}$ is the partial regressive coefficient, $X_{1}$ is the independent and $\mathrm{Y}$ is the dependent or predictor variable. The model coefficients can be found by the least-squares method, the best-fitting line for the observed data is determined by minimizing the sum of the squares of the deviations from each data point to the line. In this study the least-squares estimates are computed by Minitab® statistical software.

3.4.2. Artificial Neural Network Model: The ANN is basic mathematical model of the human brain contains inter-connected neurons to each other. Similar to the human brain, the ANN network is able to recognize the pattern in a data and fit well for nonlinear characteristics of a system. Application of the ANN is a common solution for many engineering problems containing nonlinear systems. Not only, the implementation of ANN for civil engineering problems such as water resources and hydrology is applicable but also, it is quite promising for solution of nonlinear, multivariate and complex characteristics of transportation problems. The ANN consists of several data processing nodes called neurons. Basically the neurons or nodes are grouped in several layers called input, output and one or several hidden layers. A three-layer artificial neural network is shown in Figure 1.

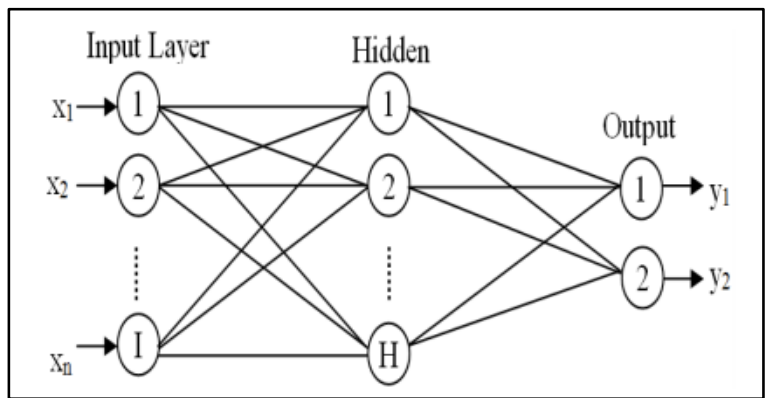

Figure 1. Diagram of an ANN Structure

After the training process, network performance can be evaluated with a validation data mostly in the manner of mean square error (MSE) determined with the equation given below:

$$
M S E=\frac{\left(O_{e}-O_{m}\right)^{2}}{n-1}
$$

Where $\mathrm{O}_{\mathrm{e}}$ is the expected value, $\mathrm{O}_{\mathrm{m}}$ is the predicted value from the model and $\mathrm{n}$ is the size of the data-set. To achieve optimal learning and avoid overtraining, excessive care should be taken while modeling. Determination of the numbers of the hidden layer neurons is also considered to be an important factor influencing the ANN performance as with high neuron numbers, training will take considerable time and over fitting of the data is quite possible.

\section{Analysis and Discussion}

\subsection{Information about the Seaport}

Izmir seaport, operated by the Turkish General Directorate of State Railways (TCDD), is an important export hub in the western Anatolia region of the Turkey [11]. Izmir is the 
third largest city of Turkey with a population over 4 million of inhabitants. It is an economically important city with its exports corresponded to $6 \%$ and its imports $4 \%$ of Turkey's foreign trade [12]. The seaport is connected to the railway and highway networks. Izmir seaport is a suitable node for import and export due to its strategic location. Plan and aerial views of the seaport are shown in Figure 2.
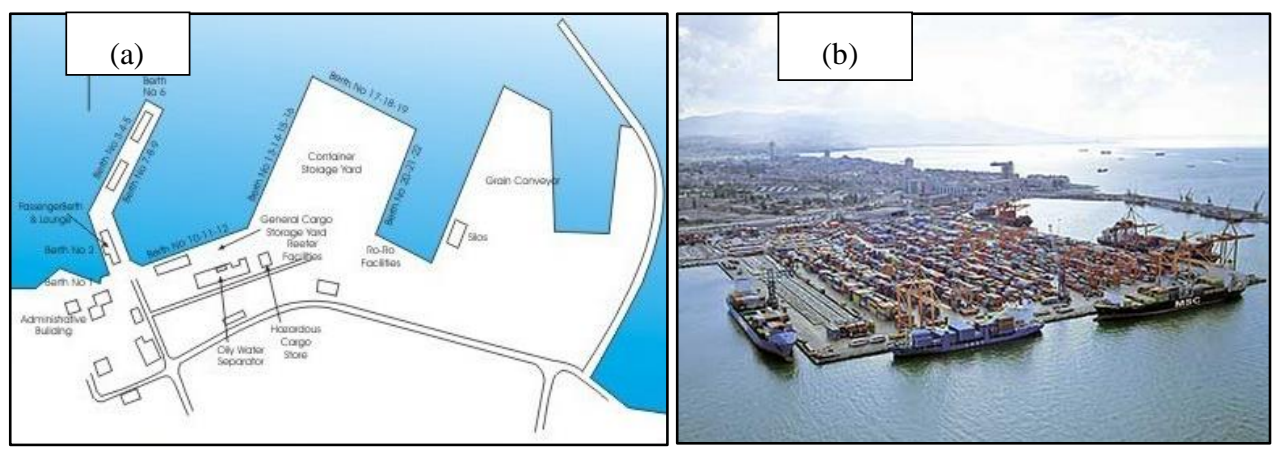

Figure 2. (A) Plan And (A) Aerial Views Of The Izmir Seaport. (Retrieved From Bookyourtransfer.Com) [13]

Not only its commercial value, thanks to the historical and touristic places scattered in the close regions, the port also has a significant passenger traffic. Some characteristic information about the Izmir seaport are shown in Table 2.

Table 2. Basic Characteristic Information Of The Izmir Seaport [14]

\begin{tabular}{ccc}
\hline $\begin{array}{c}\text { Port } \\
\text { Characteristics }\end{array}$ & \multicolumn{2}{c}{ Val } \\
ues
\end{tabular}

\subsection{Ship Traffic Projection}

For determining the future berth requirements, the number of arriving ships to the seaport was considered as the input parameter required being determined with a projection study. For this manner, an artificial neural network model was implemented simultaneously with the LR model to check if it is superior to the latter one. A three-layer model represented in Table 3 was trained with back propagation [15] and Artificial Bee Colony algorithms implemented for this study with the dependent and independent variables. Total ship traffic was used in the output layer. The optimum number of neurons in the hidden layer was determined by trials. 
Table 3. The Proposed ANN Model (TSR, 2011)

\begin{tabular}{lllll}
\hline $\begin{array}{c}\text { Predictor } \\
\text { Variables }\end{array}$ & Training & Forecasting & Retrieved from & $\begin{array}{c}\text { Variable } \\
\text { Type }\end{array}$ \\
\hline Population & $1989-2013$ & $2014-2023$ & TURKSTAT [16] & Predictor \\
Total Exports & $1989-2013$ & $2014-2023$ & MERT [17] & Predictor \\
GDP & $1989-2013$ & $2014-2023$ & TURKSTAT [16] & Predictor \\
Total Imports & $1989-2013$ & $2014-2023$ & IMF [18] & Predictor \\
Ship Traffic & $1989-2013$ & $2014-2023$ & MTMAC [19] & Target \\
\hline
\end{tabular}

For the ANN modeling, a normalization procedure is required for the input signal [20]. By implementing a standardization function, input and output signals were normalized between 0.1 and 0.9 with the Equation (16).

$$
Y_{\mathrm{n}}=0.9 \frac{\mathrm{Y}_{\mathrm{r}}-\mathrm{Y}_{\mathrm{rmin}}}{\mathrm{Y}_{\mathrm{rmax}}-\mathrm{Y}_{\mathrm{rmin}}}+0.1
$$

where $Y_{n}$ is the normalized signal, $Y_{n}$ is the raw signal $Y_{r m a x}$ and $Y_{r m i n}$ are maximum and minimum signals in the data set. Linear Regression Analysis and ANN model results were shown in Figure 3 with the past ship arrival records to the port.

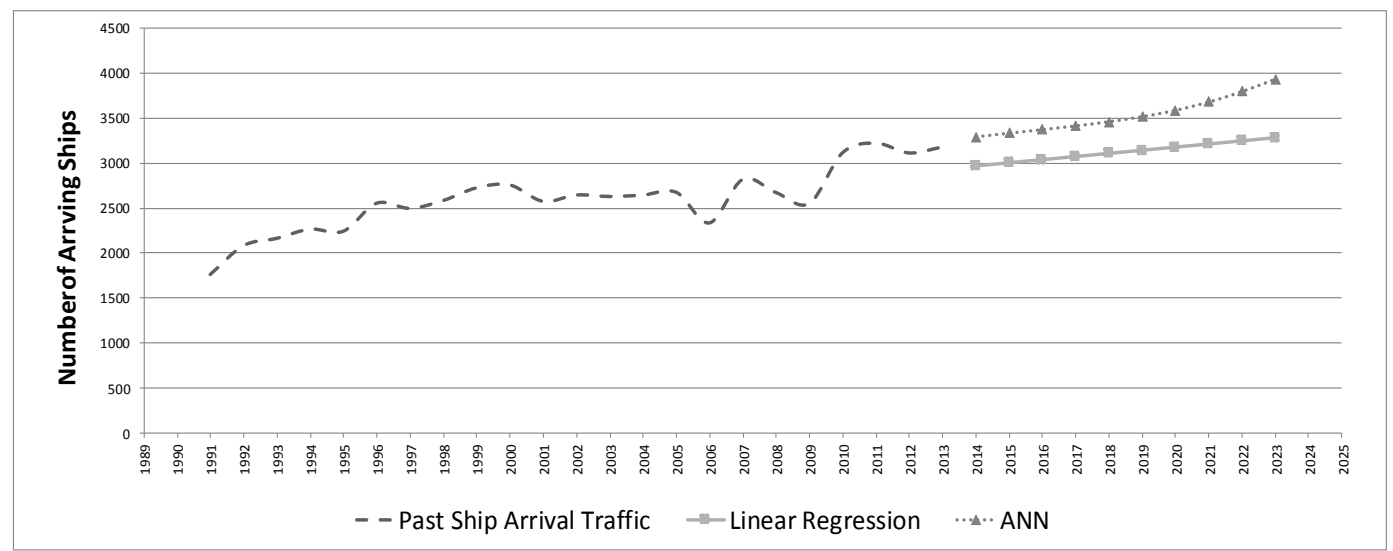

Figure 3. ANN and LR Model Results

The daily ship arrival statistics of both years 2000 and 2001 were used for determining the underlying probability distribution for the ship arrivals to the port and service time. The underlying population was determined by utilizing the Chi-square goodness of fit test in which its results are shown in Table 4. The underlying probability distribution of the arriving ships was found to be the Poison distribution and similarly berth service rate was found to be suiting well with the Erlang $\mathrm{K}=1$ distribution.

Table 4. Results of the Chi-Square Goodness of Fit Test

\begin{tabular}{lll}
\hline & Ship Arrival Distribution & Service Time Distribution \\
\hline Distribution & Poisson & Erlang K=1 \\
Chi-square Result & $\mathrm{X}_{0.95,16}^{2}=7.9$ & $\mathrm{X}_{0.95,28}^{2}=16.9<20.1<\mathrm{X}_{0.05,28}^{2}=41.3$ \\
D.O.F & 16 & 28 \\
Accept $\mathrm{H}_{0}$ & Yes & Yes \\
\hline
\end{tabular}


The coefficient for the Poisson's process $(\lambda)$, indicating the average arriving ships to the seaport, for each year (2014 to 2023) was determined by dividing the total number of ships coming each year to the number of days per year. After that, arriving ship distribution per for years 2014 to 2023 were calculated.

Berth service time distribution was also determined by using the Erlang's formula $(\mathrm{K}=1)$. The parameter (coefficient) of the Erlang's formula was taken as constant as 0.037 ship per hour and taken as constant through the years. As the first phase of the analysis, tabular method was implemented for determining the optimum berthing places. Combinations of $\mathrm{n}$ and $\mathrm{M}$ were used for each scenario in determining the possible number of berthing places. The calculations were performed for a total number of 10 years from 2014 to 2023 (See Table 5 and Table 6).

Table 5. Calculations for Deterministic Method, Obtaining the Theoretical Number of Ships for Each Case

\begin{tabular}{|c|c|c|c|c|c|c|c|c|c|c|c|c|c|c|c|c|}
\hline \multirow[b]{2}{*}{ Num. of shiprs } & \multirow[b]{2}{*}{$p(h)$} & \multirow[b]{2}{*}{$T \times p(h)$} & \multicolumn{2}{|c|}{4} & \multicolumn{2}{|c|}{5} & \multicolumn{2}{|c|}{6} & \multicolumn{2}{|c|}{7} & \multicolumn{2}{|c|}{8} & \multicolumn{2}{|c|}{9} & \multicolumn{2}{|c|}{10} \\
\hline & & & $M>n$ & $M<n$ & $M>n$ & $M<n$ & $M>n$ & $M<n$ & $M>n$ & $M<n$ & $M>n$ & $M<n$ & $M>n$ & $M<n$ & $M>n$ & $M<n$ \\
\hline 0 & 0.000 & 0.00 & & & 0.0 & & 0.0 & & 0.0 & & 0.0 & & 0.0 & & 0.0 & \\
\hline 1 & 0.000 & 0.00 & 0.0 & & 0.0 & & 0.0 & & 0.0 & & 0.0 & & 0.0 & & 0.0 & \\
\hline 2 & 0.000 & 0.03 & 0.1 & & 0.1 & & 0.1 & & 0.2 & & 0.2 & & 0.2 & & 0.3 & \\
\hline 3 & 0.000 & 0.15 & 0.1 & & 0.3 & & 0.4 & & 0.6 & & 0.7 & & 0.9 & & 1.0 & \\
\hline 4 & 0.001 & 0.52 & 0.0 & 0.0 & 0.5 & & 1.0 & & 1.6 & & 2.1 & & 2.6 & & 3.1 & \\
\hline 5 & 0.004 & 1.44 & & 1.4 & 0.0 & 0.0 & 1.4 & & 2.9 & & 4.3 & & 5.8 & & 7.2 & \\
\hline 6 & 0.009 & 3.34 & & 6.7 & & 3.3 & 0.0 & 0.0 & 3.3 & & 6.7 & & 10.0 & & 13.3 & \\
\hline 7 & 0.018 & 6.62 & & 19.9 & & 13.2 & & 6.6 & 0.0 & 0.0 & 6.6 & & 13.2 & & 19.9 & \\
\hline 8 & 0.032 & 11.49 & & 46.0 & & 34.5 & & 23.0 & & 11.5 & 0.0 & 0.0 & 11.5 & & 23.0 & \\
\hline 9 & 0.049 & 17.73 & & 88.6 & & 70.9 & & 53.2 & & 35.5 & & 17.7 & 0.0 & 0.0 & 17.7 & \\
\hline 10 & 0.068 & 24.62 & & 147.7 & & 123.1 & & 98.5 & & 73.9 & & 49.2 & & 24.6 & 0.0 & 0.0 \\
\hline 11 & 0.086 & 31.09 & & 217.6 & & 186.5 & & 155.5 & & 124.4 & & 93.3 & & 62.2 & & 31.1 \\
\hline 12 & 0.100 & 35.98 & & 287.9 & & 251.9 & & 215.9 & & 179.9 & & 143.9 & & 108.0 & & 72.0 \\
\hline 13 & 0.107 & 38.44 & & 346.0 & & 307.6 & & 269.1 & & 230.7 & & 192.2 & & 153.8 & & 115.3 \\
\hline 14 & 0.106 & 38.14 & & 381.4 & & 343.3 & & 305.1 & & 267.0 & & 228.8 & & $\begin{array}{ll}190.7 \\
\end{array}$ & & 152.6 \\
\hline 15 & 0.098 & 35.31 & & 388.5 & & 353.1 & & 317.8 & & 282.5 & & 247.2 & & 211.9 & & 176.6 \\
\hline 16 & 0.320 & 115.09 & & 1381.1 & & 1266.0 & & 1150.9 & & 1035.8 & & 920.7 & & 805.6 & & 690.5 \\
\hline
\end{tabular}

Table 6. Calculations for Cost of the Waiting Ships in Queue, Between $7^{\text {th }}$ And $16^{\text {th }}$ Row (Between $4^{\text {th }}$ And $11^{\text {th }}$ Columns)

\begin{tabular}{|c|c|c|c|c|c|c|c|c|}
\hline & 4 & 5 & 6 & 7 & 8 & 9 & 10 & 11 \\
\hline & $925^{55}$ & $139^{33}$ & $953^{45}$ & 0 & & & & \\
\hline & $7831^{14}$ & $2069^{10}$ & $2^{15}$ & $977^{22}$ & 0 & & & \\
\hline & $5119^{32}$ & $3899^{24}$ & $9312^{34}$ & $892^{93}$ & $458^{35}$ & 0 & & \\
\hline 0 & ${ }_{0599}^{62}$ & $0132^{49}$ & $0213^{66}$ & $1632^{24}$ & ${ }^{13}$ & $247^{49}$ & 0 & \\
\hline 1 & $\begin{array}{r}10 \\
55860 \\
\end{array}$ & $3213^{86}$ & $\begin{array}{c}10 \\
92019 \\
\end{array}$ & $\begin{array}{c}49 \\
0352 \\
\end{array}$ & $\begin{array}{r}{ }^{32} \\
0491 \\
\end{array}$ & 3607 $^{17}$ & $180^{62}$ & 0 \\
\hline 2 & \begin{tabular}{|c}
16 \\
31602 \\
\end{tabular} & $\begin{array}{c}13 \\
66987 \\
\end{array}$ & $\begin{array}{r}16 \\
30239 \\
\end{array}$ & $0^{85}$ & $\begin{array}{r}60 \\
8362 \\
\end{array}$ & $9510^{38}$ & $6116^{20}$ & $968^{71}$ \\
\hline 3 & $\begin{array}{r}23 \\
23599 \\
\end{array}$ & $\begin{array}{c}19 \\
82096 \\
\end{array}$ & $\begin{array}{r}22 \\
40466 \\
\end{array}$ & $\begin{array}{c}13 \\
11522 \\
\end{array}$ & $\begin{array}{c}{ }^{99} \\
2805 \\
\end{array}$ & $7064^{69}$ & $6781^{43}$ & ${ }^{22}$ \\
\hline 4 & $\begin{array}{r}30 \\
86383 \\
\end{array}$ & $\begin{array}{r}26 \\
68601\end{array}$ & $\begin{array}{r}28 \\
76119 \\
\end{array}$ & $\begin{array}{r}18 \\
45471 \\
\end{array}$ & $\begin{array}{r}14 \\
50475 \\
\end{array}$ & $\begin{array}{r}10 \\
78456 \\
\end{array}$ & $1^{74}$ & $4580^{45}$ \\
\hline 5 & $\begin{array}{r}38 \\
63292\end{array}$ & $\begin{array}{r}33 \\
74882\end{array}$ & $\begin{array}{r}51 \\
77915\end{array}$ & $\begin{array}{r}24 \\
10496\end{array}$ & $\begin{array}{r}19 \\
44872 \\
\end{array}$ & $\begin{array}{r}15 \\
02225\end{array}$ & $\begin{array}{c}10 \\
95035\end{array}$ & $7092^{73}$ \\
\hline 6 & $\begin{array}{r}66 \\
25447 \\
\end{array}$ & $\begin{array}{r}59 \\
06858 \\
\end{array}$ & $\begin{array}{r}51 \\
77915 \\
\end{array}$ & $\begin{array}{r}44 \\
82112 \\
\end{array}$ & $\begin{array}{r}37 \\
86309 \\
\end{array}$ & $\begin{array}{r}31 \\
13482 \\
\end{array}$ & $\begin{array}{c}24 \\
76113 \\
\end{array}$ & $\begin{array}{r}18 \\
87990 \\
\end{array}$ \\
\hline
\end{tabular}

The cost of idle ships for the case of berthing places are full was determined by multiplying the cost of a waiting ships with the entities of the Table 5. The total cost of idle berths were determined by summing the entities of the $M>n$ row and multiplying it 
with the idle berth cost. The cost of idle berth and ship waiting for a free berthing place were determined as $\$ 1700 /$ day and $\$ 5000 /$ day for this study. The optimum number of berthing place was determined with considering the minimum total cost (total cost of idle berths + total cost of queuing ships) for each berth number. The total costs of berths for year 2015 to 2023 were calculated and the optimum number of berths was determined in Figure 4.

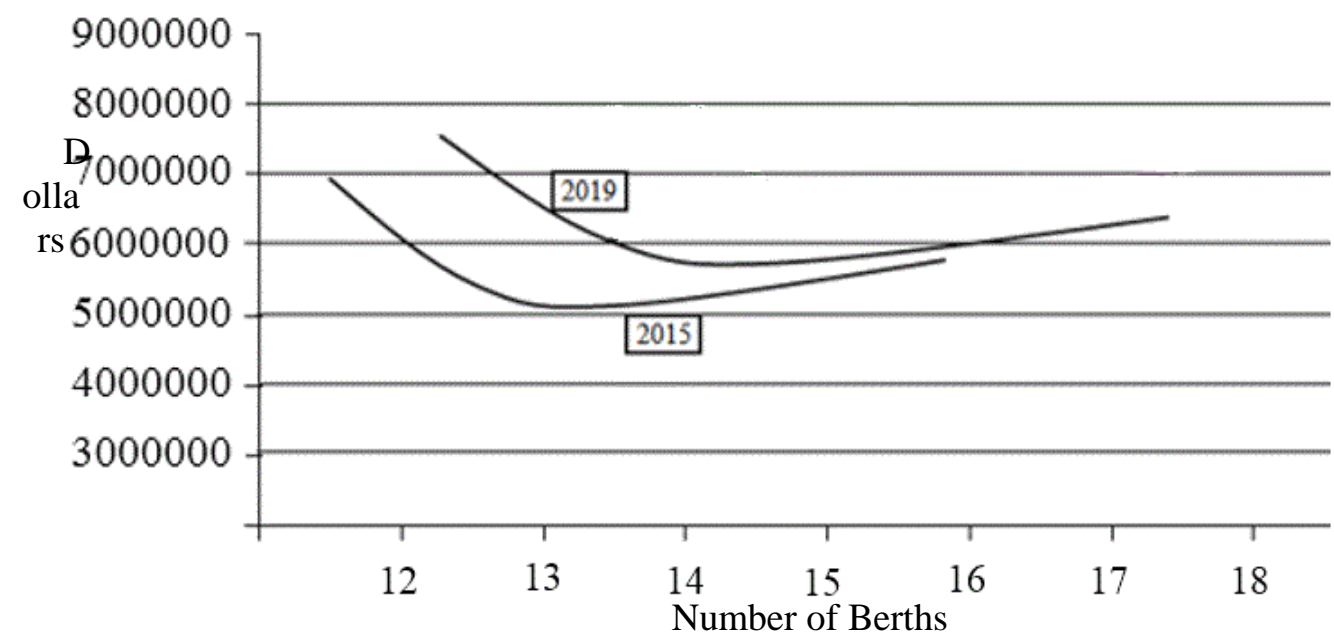

Figure 4. Total Costs of Various Numbers of Berths for Years 2015, 2019 And 2023 (The Case of 16 Arriving Ships)

The optimum number of berths was also determined by implementing the queuing theory. The calculating procedure was iterated for each year from 2015 to 2023 with the increasing number of ships arriving to the seaport. As an example for the year 2015, $\mathrm{T}=8640$ indicated the total work hours as the seaport is operational per year. $\mathrm{N}$ was considered 3568 from the linear regression model for ship arrivals. The calculations for year 2015 were shown in Table 7.

Table 7. Calculations of the Queuing Model for Year 2015 By Queue Theory

\begin{tabular}{|l|l|l|l|l|l|}
\hline \# of Berths: & 12 & 13 & 14 & 15 & 16 \\
\hline $\mathrm{L}_{\mathrm{q}}$ & 2.96 & 1.21 & 0.55 & 0.26 & 0.12 \\
\hline $\mathrm{L}_{\mathrm{s}}$ & 13.21 & 11.46 & 10.80 & 10.51 & 10.37 \\
\hline $\mathrm{W}_{\mathrm{q}}$ & 7.73 & 3.17 & 1.44 & 0.68 & 0.32 \\
\hline $\mathrm{W}_{\mathrm{s}}$ & 34.51 & 29.95 & 28.22 & 27.46 & 27.10 \\
\hline $\mathrm{CS}(\$)$ & $5,323,171$ & $2,183,504$ & 993,816 & 468,070 & 221,444 \\
\hline $\mathrm{C}_{\mathrm{b}}(\$)$ & $7,560,000$ & $8,190,000$ & $8,820,000$ & $9,450,000$ & $100,800,00$ \\
\hline $\mathrm{C}_{\mathrm{t}}(\$)$ & $12,883,171$ & $10,373,504$ & $9,813,816$ & $9,918,070$ & $10,301,444$ \\
\hline
\end{tabular}

By investigating the table, the optimum total number of berthing places was found as 14 for 3307 arriving ships in 2015. In Figure 5 optimum number of berths and related costs are shown considering the queuing theory model. The costs for optimum number of berths are shown in Figure 6 considering deterministic method. 


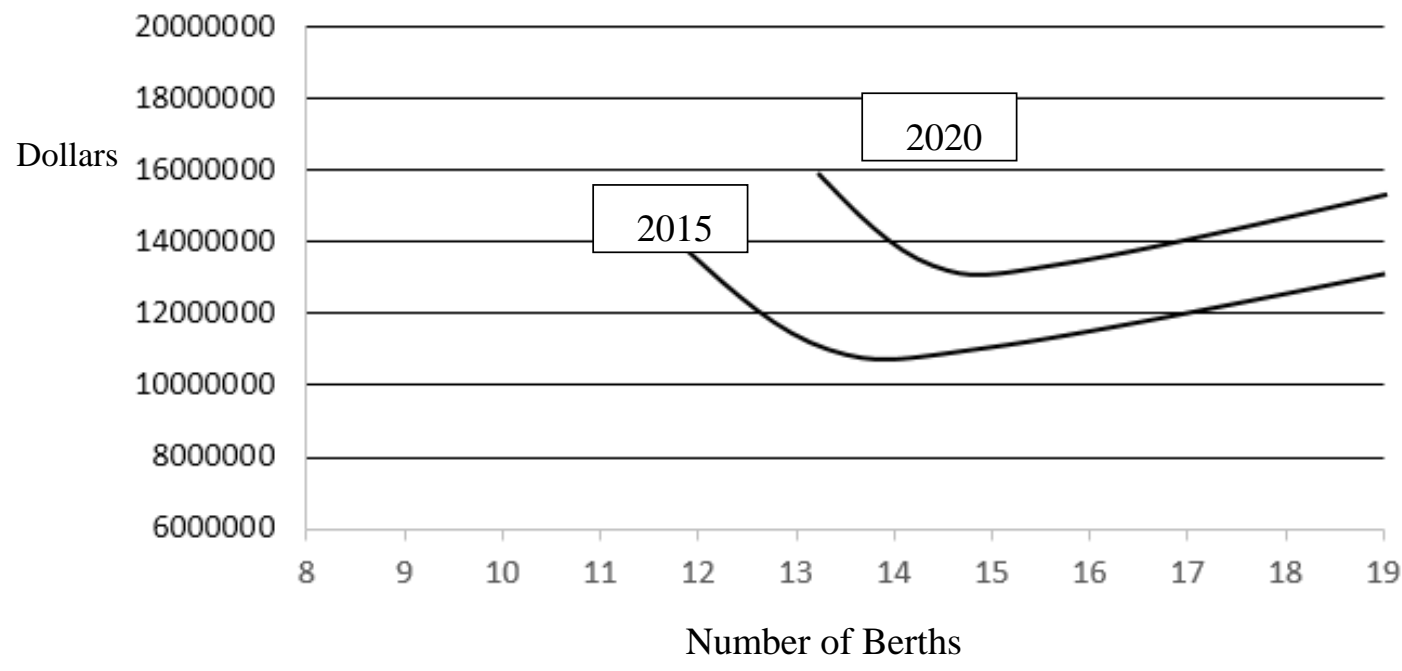

Figure 5. Total Costs of Various Number of Berths and Indication of Optimum Berth Number for Years 2015, 2020 Considering Queuing Theory Model

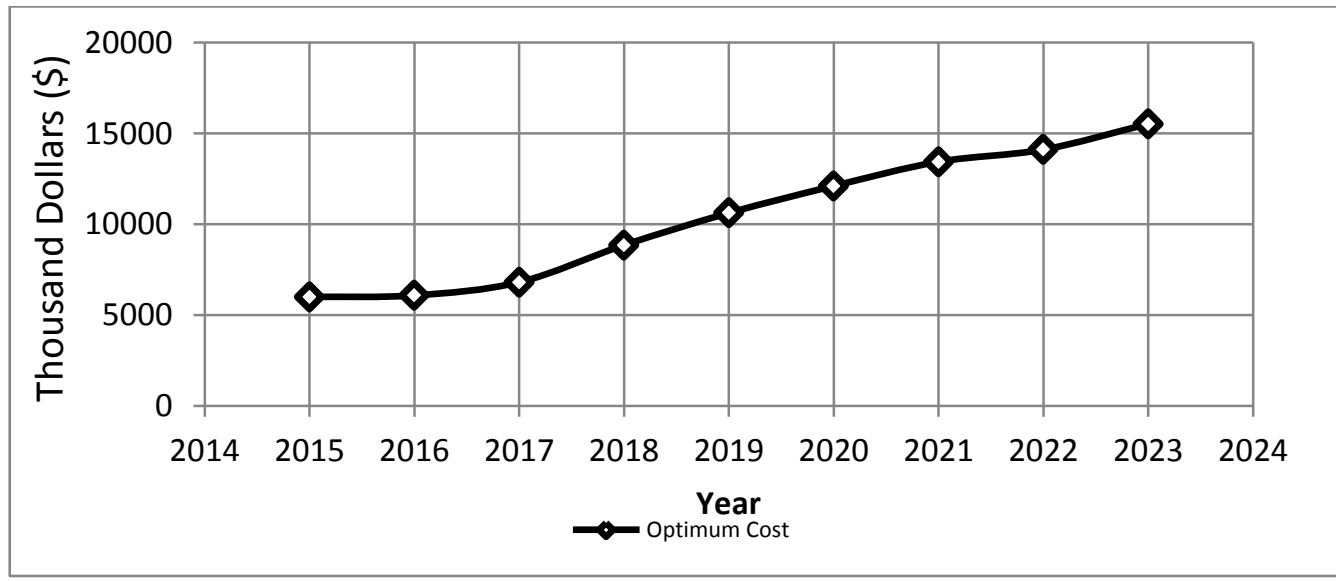

Figure 6. Optimum Costs Considering Deterministic Model

\section{Conclusion}

In the scope of this study, the optimum number of berths places was calculated for the Izmir seaport by implementing the queuing model and an alternative tabular methodology. To obtain a better ship traffic projection, both the ANN and the linear regression models were implemented. The ANN was found to be the best model comparing with the linear regression so its output data was used for the next phase of the study. Optimum berth numbers evaluated for both queuing theory and alternative methodology are shown in Figure 5. 


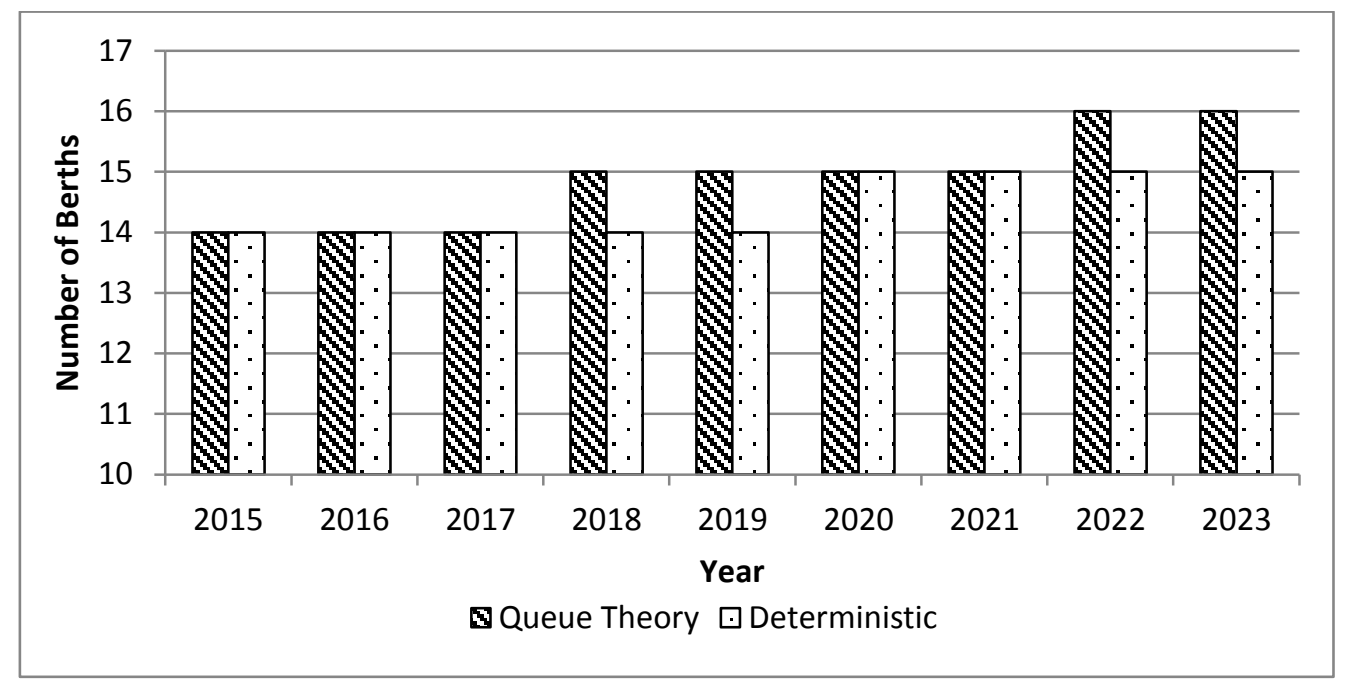

Figure 5. The Optimum Number of Berths for Two Different Methods

It could be seen in the Figure 5 that, queuing theory gave more accurate and sensible results than those of the tabular methodology. The total number of berths for the seaport was expected to be increased with the increasing number of ship arrivals through the years. As a note, in this study, the Erlang parameter representing the service time spent for each ship for a single berth was taken as constant through the years indicated that the average handling time for arriving ships was taken constant. In fact, with the technological improvement a shortening of this time can be expected through the years. As a result, this study demonstrated the utilization of the queuing theory for predicting the needs of berth for the future operational service of a seaport. As a final note, simulations techniques can be implemented to consider this problem as a future study.

\section{References}

[1] C. H. Plumlee, “Optimum Size Seaport,” J. Waterw. Harb. Div., vol. 92, no. 3, (1966).

[2] R. Moorthy and C. P. Teo, "Berth management in container terminal: The template design problem," in Container Terminals and Cargo Systems: Design, Operations Management, and Logistics Control Issues, (2007), pp. 63-86.

[3] L. Li, Q. Meng, and W. Bei, "Based on queuing theory to solve the optimization number of berth," in 2010 3rd International Symposium on Knowledge Acquisition and Modeling, KAM 2010, (2010), pp. 424-427.

[4] S. Nicolau, "Berth Planning by Evaluation of Congestion and Cost," J. Waterw. Harb. Div., vol. 93, no. 4, pp. 107-132, (1967).

[5] P. M. Morse, Queues, Inventories and Maintenance. (1958).

[6] Thomas J. Fratar, Alvin S. Goodman, and J. Austin E. Brant, "Prediction of Maximum Practical Berth Occupancy," Trans. Am. Soc. Civ. Eng., vol. 126, no. 4, pp. 632-641, (1961).

[7] A. Eren and Ü. Gökkuş, "İzmir Limani Konteyner Kapasitesi ve Trafik Projeksiyonu," in Advances in Civil Engineering, (1997) (In Turkish).

[8] E. Budak, "Optimization of port capacity and storage areas," (2002).

[9] P. J. Connor-linton, "Chi Square Tutorial," Linguistics, pp. 1-10, (2006).

[10] G. A. F. Seber and J. A. Lee, Linear Regression Analysis. (2003), p. 583.

[11] World Fact Book, "The World Fact Book: Turkey," (2015). [Online]. Available: https://www.cia.gov/library/publications/the-world-factbook/geos/tu.html. [Accessed: 11-Feb-2015].

[12] Turkish Exporters Assembly, "Economy and Foreign Trade Report," (2014) .

[13] Bookyourtransfer.com, "Bookyourtransfer." [Online]. Available: http://www.bookyourtransfer.com/photos/turkey/izmir_port.jpg. [Accessed: 25-Feb-2014].

[14] Turkish State Railways, "Turkish State Railways: İzmir Seaport," 2011. [Online]. Available: http://www.tcdd.gov.tr/tcdding/izmir_ing.html. [Accessed: 11-Feb-2015].

[15] Y. LeCun, "A theoretical framework for Back-Propagation," in Proceedings of the 1988 Connectionist Models Summer School, (1988), pp. 21-28.

[16] TURKSTAT, "Statistical Data: Turkey," (2014). [Online]. Available: http://www.turkstat.gov.tr/UstMenu.do?

[17] Ministery of Economy Repuplic of Turkey, “2023 Turkish Action Plan of Trade Strategy,” (2010). 
[18] International Money Fund, "IMF Data Summary," 2014. [Online]. Available: http://www.imf.org/external/data.htm. [Accessed: 07-Jun-2015].

[19] Ministry of Transport Maritime Affairs and Communications, "Ministry of Transport Maritime Affairs and Communications Database," (2014) .

[20] C. Gershenson, “Artificial Neural Networks for Beginners,” Networks, vol. cs.NE/0308, p. 8, (2003).

\section{Authors}

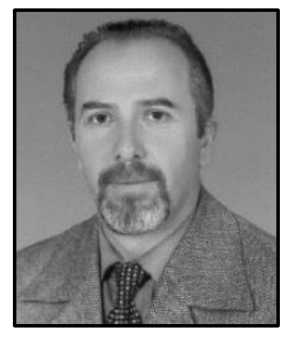

Dr. Ümit Gökkuş, is currently working as a Professor in the Manisa Celal Bayar University, Civil Engineering Department Head of Hydraulic Division. He had his PhD degree from Dokuz Eylül University in Turkey and holds a MSc degree in Civil Engineering Department from the Middle East Technical University. His current research interests include Coastal and Port Engineering, Offshore Pipeline Engineering, Fluid-Structure Interaction and Marine Transportation.

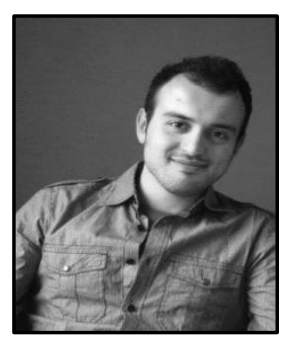

Mehmet Sinan Yıldırım, is currently working as a research assistant at Manisa Celal Bayar University, Civil Engineering Department- Hydraulic division. He is continuing his $\mathrm{PhD}$ studies in Civil Engineering Department same University. He holds MSc and bachelor's degrees from the Civil Engineering department at Middle East Technical University. 
International Journal of Hybrid Information Technology Vol.8, No.9 (2015) 